\title{
A Evolução dos Modos de Gestão do Desenvolvimento de Produtos
}

\author{
Gilberto Dias da Cunha, Dr. \\ Pontifícia Universidade Católica do Rio Grande do Sul \\ Faculdade de Engenharia \\ Departamento de Engenharia de Produção \\ gcunha@pucrs.br
}

\begin{abstract}
Este artigo apresenta uma análise da evolução das diversas abordagens em gestão do desenvolvimento de produto. É efetuado um resgate dos métodos (e algumas técnicas associadas) historicamente desenvolvidos. É também realizada uma breve avaliação da contribuição das diversas áreas de conhecimento atuantes no cenário do desenvolvimento de produtos. Ao final, são apresentados os aspectos mais relevantes com relação à gestão do desenvolvimento de produtos atualmente em discussão.
\end{abstract}

Palavras-chave: gestão do desenvolvimento de produtos; gestão do ciclo de vida de produtos

This work presents an analysis on the evolution of the diverse approaches for the product development management. It makes retrieval on the methods (and some related techniques) historically devised. It is also made a brief evaluation on the contribution from the diverse knowledge areas acting on the product development scenario. At last there are addressed the most remarkable issues regarding product development and management currently under discussion.

Keywords: product development and management; product lifecycle management

\section{Introdução}

Este trabalho pretende ser útil aos profissionais das diferentes áreas envolvidas no desenvolvimento de produtos, numa abrangência pretensamente multidisciplinar, no sentido de proporcionar um resgate dos aspectos históricos inerentes à gestão do desenvolvimento de produtos. $\mathrm{O}$ enfoque a ser conferido a esta análise será, tanto quanto possível, o de retratar o ponto de vista do gestor desta atividade empresarial, dentro de um contexto evolutivo. Para tanto, será inicialmente efetuada a revisão de alguns conceitos fundamentais inerentes à atividade do desenvolvimento de produtos, passando-se, na seqüência, a uma análise mais detida dos métodos mais atuais de gestão.

\section{Desenvolvimento de produtos: Uma Perspectiva Histórica}

Historicamente, foi, aproximadamente, a partir do final do Século XIX, que começou a ser notado um interesse mais acentuado por métodos e técnicas orientados especificamente ao desenvolvimento de produtos. A indústria despertou paulatinamente para a importância deste novo domínio de conhecimento, o qual passou a atingir posição de destaque ao final do Século XX.

Ao longo deste processo, ocorreu, não apenas, um progressivo incremento da base do conhecimento acumulada relativamente ao desenvolvimento de produtos, de todos os tipos, classes e origens, mas também o papel do profissional envolvido com esta atividade foi sofrendo alterações. Inicialmente, uma atividade centrada no trabalho individual, circunscrita, normalmente, a uma única origem em 
termos de área de conhecimento, viria a ser organizada, mais tarde, com o concurso dos esforços concertados de profissionais de várias áreas, num esforço de trabalho articulado e colaborativo.

Desde o princípio da Revolução Industrial, fenômeno intimamente relacionado ao aumento de demanda ocasionado pela explosão demográfica, a prioridade no desenvolvimento da atividade industrial centrou-se na solução de problemas relacionados, inicialmente, ao processo de fabricação, e, posteriormente, à organização da produção. Apenas, após, o crescimento da complexidade tecnológica dos produtos haver atingido um patamar que demandava análises mais detidas e aprofundadas, é que estes vieram a constituir objeto de preocupação específica no ambiente industrial.

Deve-se notar que os focos de atenção do mundo empresarial que foram surgindo sucessivamente apenas vieram a se adicionar aos anteriormente existentes (não os eliminando) - ver Figura 1.

Desta forma, as obras de Frederick W. Taylor e de seus contemporâneos inauguraram uma fase de atenções para com o incremento da produtividade, obtida a partir do esforço de reorganização dos meios produtivos. Já Henry Ford viria a aliar os conceitos então em voga à aguda percepção da possibilidade de popularização do produto automóvel, desde que oferecido a preços capazes de atingirem os interesses de um mercado potencial em formação. A evolução da tecnologia de fabricação e o crescimento dos mercados dirigiram as atenções aos problemas de perda da qualidade do produto, suscitando o interesse pelas técnicas de inspeção, que viriam a demandar, ainda, o desenvolvimento da tecnologia de instrumentação e de mensuração.

Mais tarde, em grande parte, como fruto do desenvolvimento tecnológico, a preocupação com a concepção do produto passa a ocupar lugar de destaque (Figura 2). Primeiramente, em termos da sua constituição funcional-estrutural, dando origem ao estudo dos sistemas técnicos. Num segundo momento, aparece como elemento capaz de garantir a posição de mercado da empresa em tempos de acirramento da disputa por mercados globais, através da satisfação das necessidades e desejos do cliente. Finalmente, o desenvolvimento de novos produtos passa a constituir objeto de reestruturação do próprio negócio da empresa.

A partir do momento em que o foco das atenções volta-se para o produto, constata-se o surgimento de um número significativamente maior de peças na literatura técnica versando sobre o projeto das mais diversas categorias dos mesmos. É também natural que, do universo de áreas e temas abrangidos pelo desenvolvimento de produtos, fosse o projeto de engenharia o mais privilegiado, pois os maiores desafios ao sucesso dos produtos (e, por conseqüência, dos empreendimentos industriais) relacionavam-se com a garantia da obtenção de sua funcionalidade básica e de sua estabilidade estrutural.

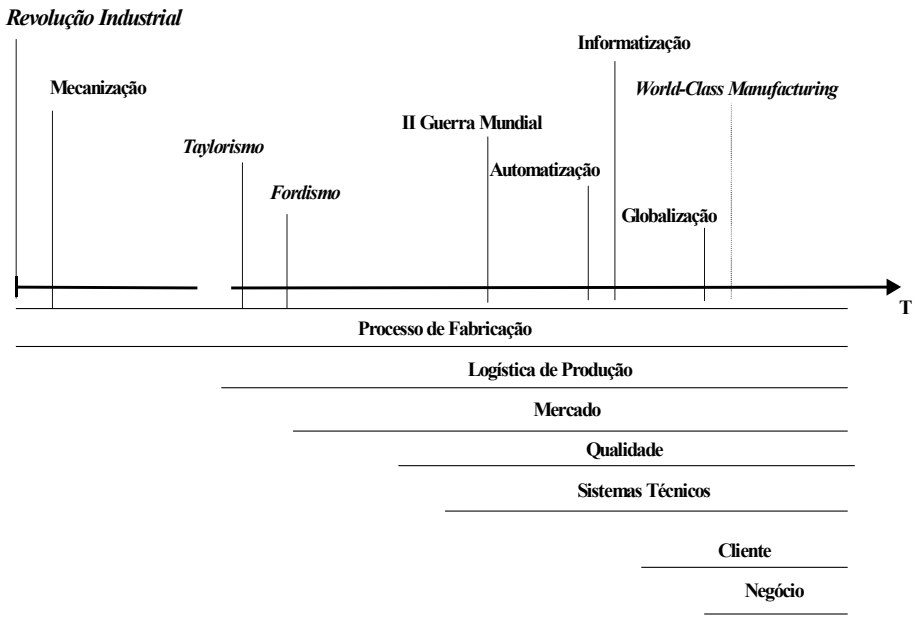

Figura 1. Progressão do foco das atenções no mundo industrial. 
Neste momento, apareceram obras constituídas basicamente por coletâneas de procedimentos relacionados com o projeto de produtos. Num primeiro momento, constituíram um nível bastante primário em termos de formalização da atividade de desenvolvimento do projeto, passando, mais tarde, a propostas mais elaboradas de sistematização da atividade projetual.

Após, surgiram as primeiras obras orientadas ao estudo do comportamento do consumidor, também num nível relativamente primário, iniciando estudos que viriam, mais recentemente, a relacioná-lo a oportunidades de mercado e de desenvolvimento de características específicas no produto. Com o aumento da competitividade entre as empresas, o foco mercadológico tornou-se prioritário, aparecendo a figura do encantamento do cliente como elemento central no cenário do desenvolvimento de produtos.

Os anos 80 trouxeram à tona a necessidade de adaptação a uma nova situação de mercado, com o surgimento dos mercados globais, que implicou a concorrência com um número crescente de empresas, e, em decorrência disso, o aparecimento de um consumidor cada vez mais exigente, demandante de uma maior diversidade de opções de produto, a intervalos de tempo progressivamente menores. A resposta a este desafio veio através do surgimento da engenharia concorrente.

Ainda nesta década, o desenvolvimento da microinformática proporcionaria o surgimento de diversas tecnologias de base computacional que viriam a ocupar espaço definitivo como suporte à atividade do desenvolvimento de produtos.

Os anos 90 viriam a apontar para a necessidade de se integrar o trabalho interfuncional em grande escala, dada a complexidade das questões inerentes ao desenvolvimento de produtos, dando forma ao conceito de desenvolvimento integrado de produto, baseado no trabalho colaborativo.

Finalmente, já ao final do Século XX, a preocupação com a gestão do portfolio de produtos, passa a ocupar destaque entre as preocupações fundamentais das empresas, conduzindo a que o foco na inovação em produto passasse a ser incorporado ao planejamento estratégico das mesmas.

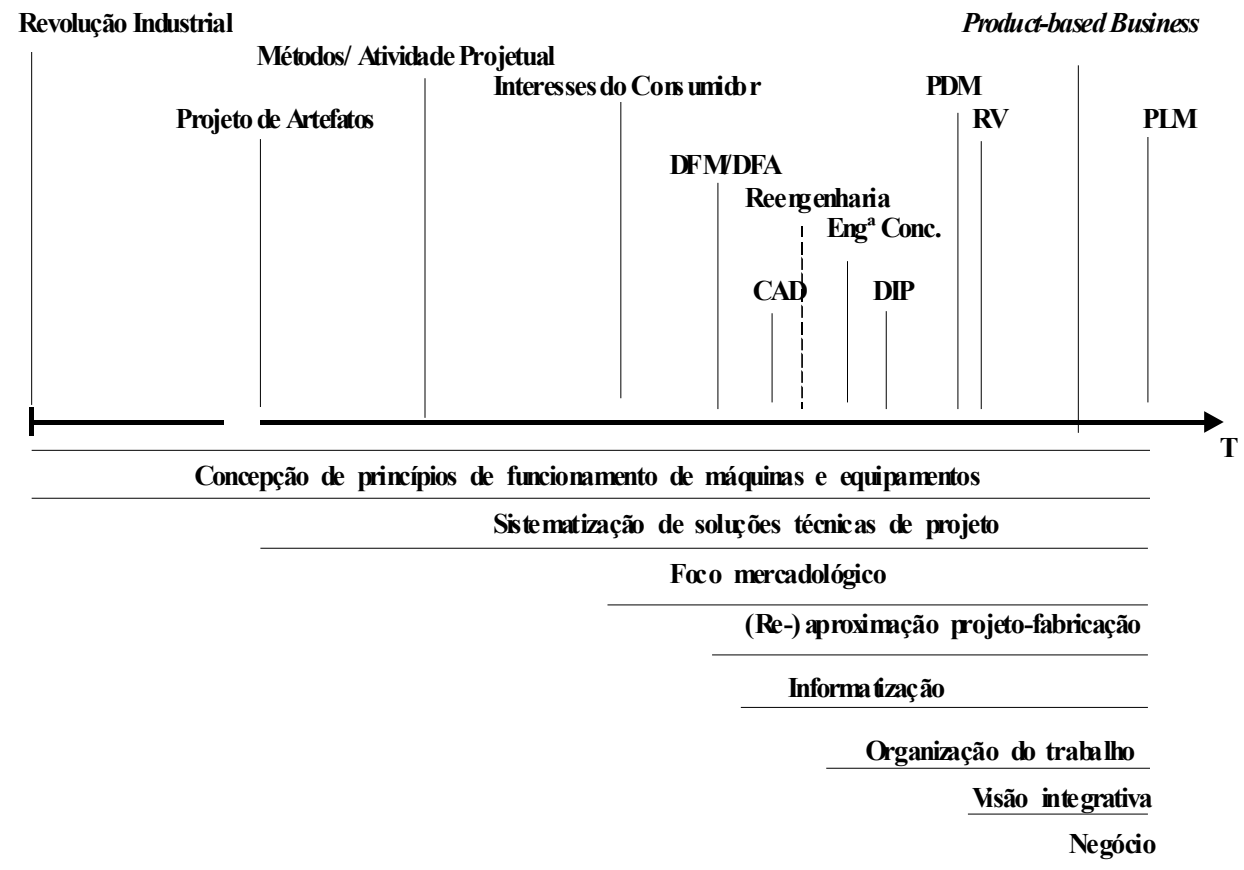

Figura 2. Métodos e técnicas em desenvolvimento de produtos: linha de tempo. 


\section{A diversidade de áreas de conhecimento atuantes no desenvolvimento de produtos}

Desde o princípio, a gestão do desenvolvimento de produto, sob uma perspectiva empresarial, caracterizou-se como uma atividade em que assumia papel fundamental a coordenação da multiplicidade de pontos de vista dos diversos profissionais envolvidos, com formação nas mais diversas áreas do conhecimento. Freqüentemente, isso implicava a gestão de conflitos relacionados com visões diferenciadas a respeito da concepção de produto ou da forma de projetá-lo, não raramente, redundando em disputas pela primazia na condução do projeto e na concretização das características do produto.

Assim, profissionais das áreas mais relacionadas com a concepção das características físicas do produto, como engenheiros e designers, tendem a ter a sua visão de produto concentrada nas questões inerentes à obtenção da sua funcionalidade. Engenheiros tendem a privilegiar o foco na função prática do produto e em sua adequação estrutural, ao passo que designers têm sua percepção mais aguçada para as funções simbólica, estética e ergonômica.

Profissionais oriundos das áreas humanísticas tendem a vizualizar o produto como uma fonte de atendimento das necessidades dos seus usuários (ver Figura 3). Neste caso, a definição das características de produto deveria ser efetuada de modo a atingir os diferentes níveis de necessidades presentes nos seus diversos usuários.

Profissionais da área de Marketing vêem o produto como uma forma de satisfação dos interesses do cliente, um dos elementos fundamentais para se garantir sucesso na comercialização (ver Figura 4). Neste caso, a concepção do produto não se restringe à definição das suas características físicas constituintes, mas abrange, também, todos os demais elementos relacionados com a viabilização da sua comercialização.

Segundo Levitt (1983), o produto genérico consiste no conjunto de características técnicas que configuram o beneficio-núcleo num produto básico. No caso de um artefato, o produto genérico será o objeto físico em si; no caso de um serviço, será o conjunto de elementos básicos que permitem a prestação daquele serviço. Para que esse bem ou serviço seja disponibilizado ao cliente, deve existir um conjunto de itens esperados pelo cliente, como condições mínimas para a compra. Tal conjunto configura a dimensão do produto esperado, que engloba as condições de entrega, distribuição, garantia, serviços de instalação, manutenção, entre outros. Acima do produto esperado, aparece o produto aumentado, que abrange as formas de diferenciação do produto através da "ampliação" da oferta de benefícios do produto esperado. Esta dimensão concentra também as questões de imagem de marca, posicionamento da empresa e do produto no mercado e o seu nível de agregação de valor. E, ainda num nível mais elevado, pode-se contemplar o produto potencial que envolve todas as ampliações e transformações que o produto deverá sofrer no futuro, encerrando novas maneiras de satisfação dos clientes e de diferenciação da oferta de produtos. 


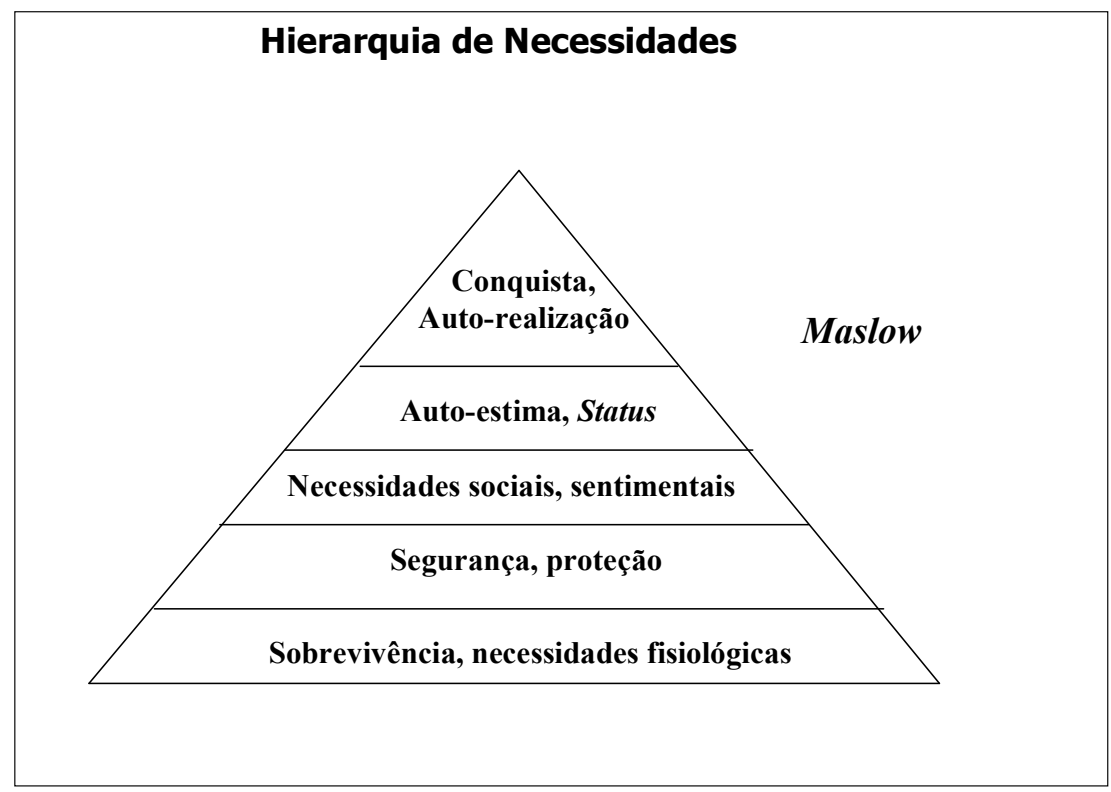

Figura 3 - Pirâmide das necessidades (segundo Maslow)

Com base nas definições preconizadas pela área de Marketing, a própria visão de produto sofreu modificações ao longo do tempo. Tanto bens, fisicamente tangíveis, como serviços, intangíveis, passaram a ser considerados formas diversas de produtos. O pacote-produto adquirido pelo cliente passou a ser considerado um composto, em proporções variáveis, de bens e serviços. Note-se que esta é uma visão incorporada, também, por exemplo, pela área de Engenharia da Produção.

Também com relação ao estudo das diferentes visões entre áreas de conhecimento, é fundamental assinalar a contribuição da área de Design (Desenho Industrial e Desenho Arquitetônico) relacionada à compreensão sobre a relação do usuário com o produto (especialmente, do produto do tipo bem). A funcionalidade do produto em termos simbólico, estético e ergonômico floresceu com o desenvolvimento das escolas orientadas ao estudo desse tema (como, por exemplo, a Bauhaus).

A Engenharia, por sua vez, sempre concentrou seus esforços na concepção estrutural do produto, tendo como pano de fundo, via de regra, a concretização da sua utilização em termos de função prática. Para tanto, contou com a disponibilização dos estudos em Física Teórica e Física Aplicada - e do desenvolvimento das tecnologias de base decorrentes. A estruturação do conhecimento relativo a produtos nos diversos ramos da Engenharia, de que é exemplo a obra de Shigley (1981), é genericamente englobada sob a denominação engenharia do produto (também se utiliza a denominação projeto de engenharia, tradução da expressão, em Língua Inglesa, Engineering Design).

\section{A sistematização da atividade de criação do produto}

Muitos autores procuraram analisar o modo pelo qual o projetista atua, compondo passo a passo a configuração definitiva de projeto do produto. Como exemplos, temos os trabalhos de Pahl \& Beitz (1996), Roozemburg \& Eekels (1995), Hubka \& Eder (1988), Pugh (1991), Clausing (1994), entre outros, que propuseram maneiras formais de descrever a atividade projetual - por exemplo, introduzindo a noção da existência de fases típicas ao longo do processo de execução da mesma.

Pela forma como definiram a execução de cada atividade, e pela própria seqüência de etapas proposta, algumas áreas de conhecimento elegeram um ou outro autor como sua referência preferencial. Os trabalhos de Ulmann (1997) e de Pahl \& Beitz, por exemplo, são referências mais aceitas pela Engenharia Mecânica, enquanto que o de Roozemburg \& Eekels é mais bem aceito por profissionais 
ligados ao Design (ver Figura 5). Assim, as metodologias de desenvolvimento de projeto costumam ter concepção de caráter, fundamentalmente, disciplinar.

\section{Produto: dîmensṍes percebidas pelo cliente}

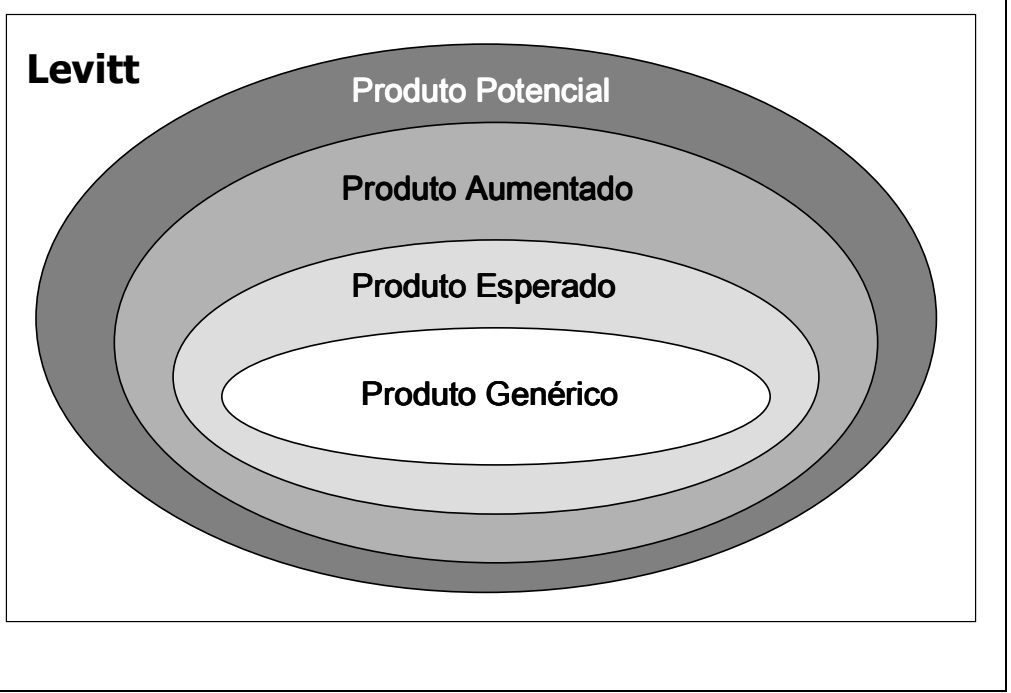

Figura 4 - Dimensões percebidas do produto pelo cliente - adaptado de Levitt (1983)

A obra de Pahl \& Beitz propõe o projeto como uma seqüência de etapas que principia pela especificação de seus objetivos, normalmente expressos na forma de grandezas quantitativas - o que se aplica bem, por exemplo, ao projeto de máquinas e equipamentos. Após, passa pela concepção das soluções de engenharia para o projeto com base na criatividade e na consulta a soluções anteriores desenvolvidas disponíveis - proposta também detalhada por French (1985); pela definição da configuração estrutural do produto (encorpação de projeto, mais conhecida como projeto preliminar); e, finalmente, pelo detalhamento desta.

Já Roozemburg \& Eekels entendem que o princípio da atividade projetual dá-se pelo contato mais direto com o futuro usuário em potencial do produto, para percepção da destinação pretendida para o mesmo. Para tanto, assumem que o projetista estaria suficientemente bem preparado, apto a interpretar os interesses do cliente, bem como para vir a traduzi-los na forma de um objeto projetável. A seqüência dos procedimentos prevê inicialmente a síntese de novas soluções de projeto a partir da informação levantada na etapa anterior, também contando com a criatividade e a eventual consulta a soluções conceituais anteriormente elaboradas. Após, ocorre uma simulação de utilização das diversas opções de projeto concebidas, conduzindo a uma avaliação final das mesmas, para seleção da mais adequada.

Já a visão da área de Marketing é expressa através do trabalho de autores como Kotler (1997) ou Crawford \& DiBenedetto (2000). Kotler agrega novos conjuntos de etapas à atividade projetual: um primeiro, relacionado com o planejamento das características de produto, o qual deve transcorrer anteriormente à atividade projetual; um segundo, destina-se à verificação da viabilidade comercial do produto já projetado, possivelmente disponibilizado na forma de protótipo. 


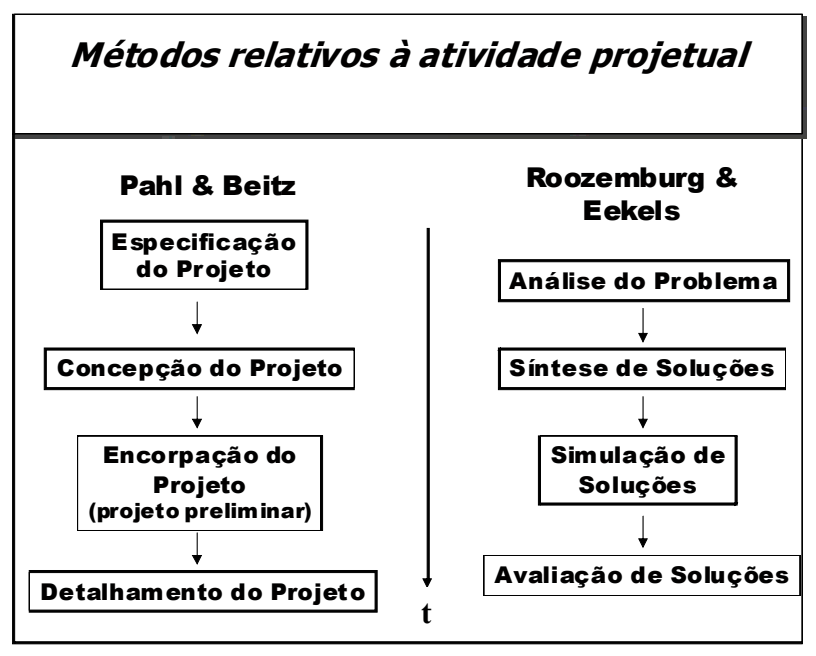

Figura 5 - Comparação entre os modelos de Pahl \& Beitz e de Roozemburg \& Eekels

Portanto, o trabalho de definição das características-alvo de produto, a serem posteriormente materializadas fisicamente a partir do trabalho dos projetistas, passa a ser efetuado por profissionais capacitados na avaliação dos interesses de mercado - isso tanto num nível macro (analistas de demanda), como micro (capacitados a compreenderem e conhecerem os interesses do cliente).

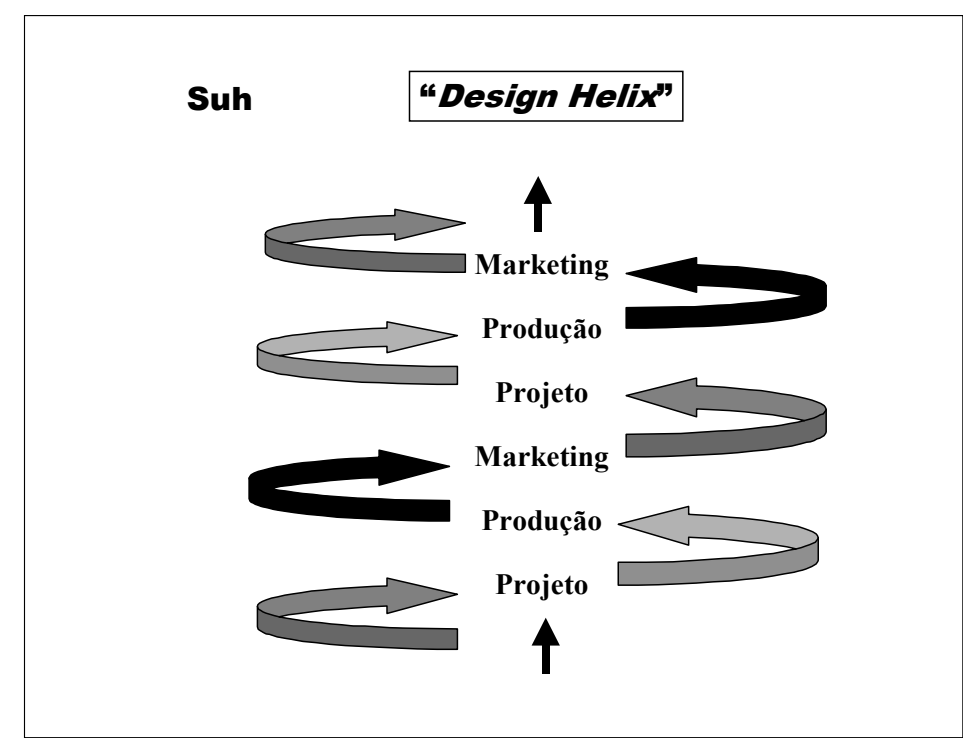

Figura 6 - Modelo de integração projeto-produção-marketing (proposto por Suh)

A realização de pesquisas de mercado eficazes e eficientes é parte inicial deste processo, como fonte provedora de idéias básicas de produto. Na seqüência, serão efetuadas a triagem dessas idéias e a geração de novos conceitos de produto a partir das idéias selecionadas. Avalia-se, ainda, a viabilidade de comercialização do produto, com estabelecimento da estratégia de Marketing a ser posteriormente implementada para o mesmo.

Já projetado o produto (por engenheiros ou designers), e disponibilizado como protótipo, testes serão realizados com o mesmo pela equipe de Marketing e junto ao mercado, para avaliação da consecução dos objetivos traçados previamente ao projeto. Se aprovado nesses testes, o produto começará a ser produzido, e sua forma de lançamento será elaborada em atendimento à estratégia de Marketing também anteriormente definida. 
Como observação geral, note-se que as situações de desenvolvimento de produto retratadas pelos diversos autores, das diversas áreas, referem-se, prioritariamente, ao projeto de novos produtos, fortemente centradas na visão de cada área de conhecimento de origem do autor. Alguns autores chegam a conceber seus modelos de estruturação da atividade do profissional desenvolvimentista de produtos na suposição de que a obtenção dos mesmos correrá quase que exclusivamente a cargo do mesmo.

Além da fraca (ou nenhuma) alusão à interação com profissionais de outras áreas, esses modelos também trazem em comum a suposição da realização das atividades dentro de uma lógica de seqüência temporal rigidamente estanque entre as etapas.

Alguns autores, ainda, apercebendo-se da eventual necessidade de serem integradas as diversas funções profissionais para a melhor consecução da obtenção dos produtos, propuseram os primeiros modelos que visavam integrá-las, como exposto em toda a obra de Baxter (1995) e, de modo mais restrito, pelo modelo de desenvolvimento de produto de Suh (1990). Este, por exemplo, propunha a integração cíclica das áreas de projeto, produção e marketing, numa forma que denominou a "hélice do Design" (ver Figura 6).

\section{Tecnologia de desenvolvimento de produtos}

A elaboração de técnicas destinadas a auxiliar o melhor exercício das diversas atividades dos diferentes profissionais envolvidos no desenvolvimento de produtos veio a acentuar-se no decorrer da segunda metade do Século XX. A maioria dessas técnicas foram concebidas, ao longo do tempo, sem qualquer espécie de vinculação entre si, o que determina que sejam apresentadas, através da literatura especializada, como elementos únicos, isolados, cuja relação com as suas congêneres raramente é analisada ou explicitada. Para o gestor do desenvolvimento de produtos, representa uma dificuldade adicional a percepção e o tratamento desta situação.

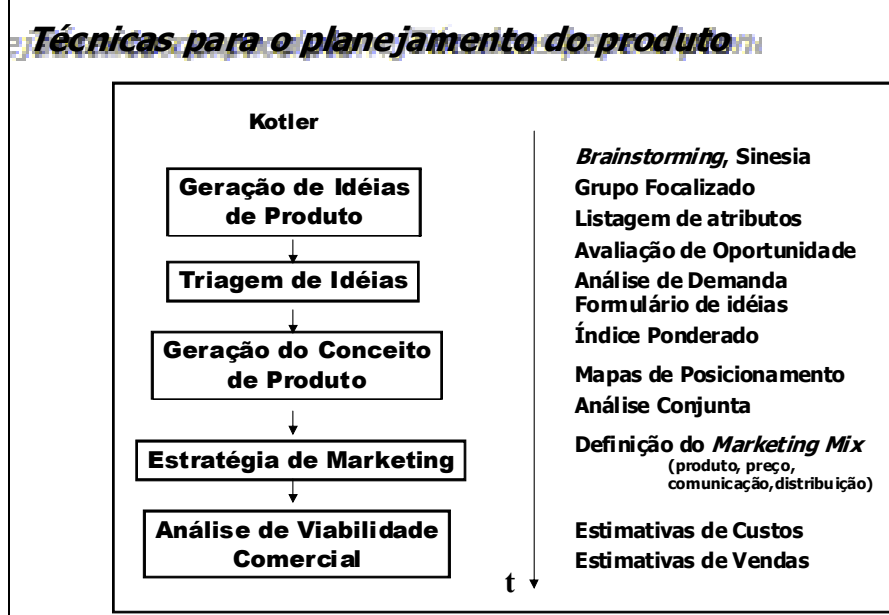

Figura 7 - Técnicas para o planejamento do produto, estruturadas sobre o modelo de Kotler

Além disso, a opção pela aplicação de uma ou outra técnica ficará também condicionada a um conhecimento adequado do momento mais adequado para sua aplicação, da sua capacidade de produzir resultados, da eventualidade da existência de dependência quanto ao tipo ou à categoria de produto em desenvolvimento e das exigências quanto a recursos de toda ordem para o seu emprego: tecnológicos, materiais, econômico-financeiros, humanos, informação e conhecimento. Tudo isso eleva a complexidade da tarefa do gestor. 
As diversas técnicas oferecidas ao gestor devem ser aplicadas, portanto, consoante a sua maior aplicabilidade dentro de uma ou de outra etapa do desenvolvimento do produto. As indicações que se fazem a seguir (conforme Figuras 7, 8 e 9) são estruturadas sobre modelos de etapas de desenvolvimento de diferentes autores, tomados como referência, não necessariamente havendo sido propostas, originalmente, por qualquer dos mesmos.

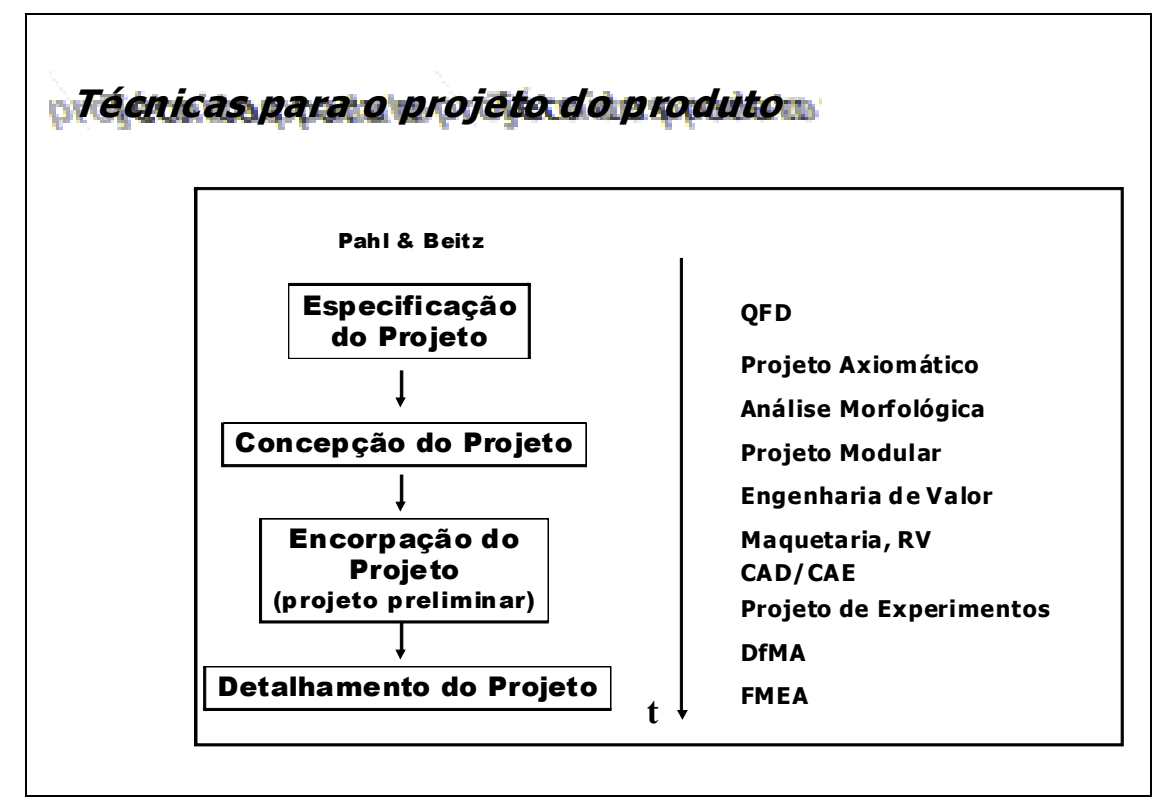

Figura 8 - Técnicas para o projeto do produto, estruturadas sobre o modelo de Pahl \& Beitz

No caso das técnicas aplicáveis ao planejamento de produto, pode-se utilizar o modelo proposto por Kotler, por exemplo (Figura 7). Entre essas técnicas, listam-se brainstorming, grupo focalizado, listagem de atributos, formulário de idéias, técnica do índice ponderado, técnicas estatísticas de análise de demanda, mapas de posicionamento, análise conjunta, definição do marketing mix $\mathrm{e}$ técnicas de estimativa de custo e de vendas.

Quanto às diversas técnicas aplicáveis ao projeto do produto, pode-se utilizar, por exemplo, o modelo de estruturação de etapas proposto por Pahl \& Beitz (ver Figura 8). Entre as técnicas mais comuns, condicionadas ao campo de desenvolvimento do produto, encontram-se, por exemplo, o desdobramento da função qualidade (QFD), o projeto axiomático, a análise morfológica, o projeto modular, a engenharia de valor, técnicas de maquetaria (incluindo a realidade virtual), os sistemas computacionais de apoio ao projeto (computer-aided design - CAD; computer-aided engineering $\mathrm{CAE}$ ), o projeto de experimentos (DOE), o projeto orientado à fabricação e montagem (DfMA), a análise dos modos e efeitos de falha (FMEA).

Observe-se que o momento de aplicação das técnicas pode variar de acordo com a situação de projeto especificamente em análise. Algumas das técnicas têm apenas um momento inicial de aplicação comumente indicável (como é o caso, por exemplo, do QFD), estendendo-se, possivelmente, através das demais etapas.

Também com relação às técnicas orientadas à preparação à comercialização, podem ser associadas à aplicação de modelos de estruturação de etapas (novamente, o modelo de Kotler é recomendado - ver Figura 9). Entre essas técnicas, listam-se, a saber, distribuição de amostras, classificação comparativa, mercados simulados, mercados controlados, (utilização de) mercados-teste e análise do perfil de novos consumidores.

Ainda no campo da tecnologia, especial atenção deve ser dedicada, ainda, à questão da presença da informatização industrial na atividade de desenvolvimento de produtos ocorrida a partir da expansão e 
popularização da microinformática nos anos 80 (BLESSING, 1994). Destacou-se desde o princípio, a tecnologia computer-aided design (CAD), destinada, inicialmente, a auxiliar o trabalho de elaboração da expressão gráfica dos produtos. Mais tarde, agregaram-se a essa tecnologia outros tipos de software. Primeiramente, desenvolveram-se aplicações destinadas à operação sobre os modelos geométricos de objetos gerados a partir dos sistemas de $\mathrm{CAD}$, como é o caso dos sistemas de computer-aided engineering (CAE).

Num segundo momento, surgiram outros tipos de aplicações, destinadas ao gerenciamento da informação, como a tecnologia product data management (PDM), a workflow e a tecnologia mais atual, a de suporte à gestão da informação de ciclo de vida do produto (tecnologia product lifecycle management - PLM), interligada aos sistemas de gestão empresarial (tecnologia enterprise resources planning - ERP). A importância da utilização desses sistemas é de tal ordem que, para muitas empresas, torna-se impossível admitir a execução das atividades de desenvolvimento de produto sem o suporte do conjunto de tecnologias de base computacional. Note-se que esta última tecnologia encontra-se, ainda, em desenvolvimento, merecendo, por enquanto, certa cautela na implementação a pleno pelas empresas, especialmente, especialmente se isso vier a implicar uma excessiva dependência à sua utilização.

\section{Técnicas para a preparação à comercialização}

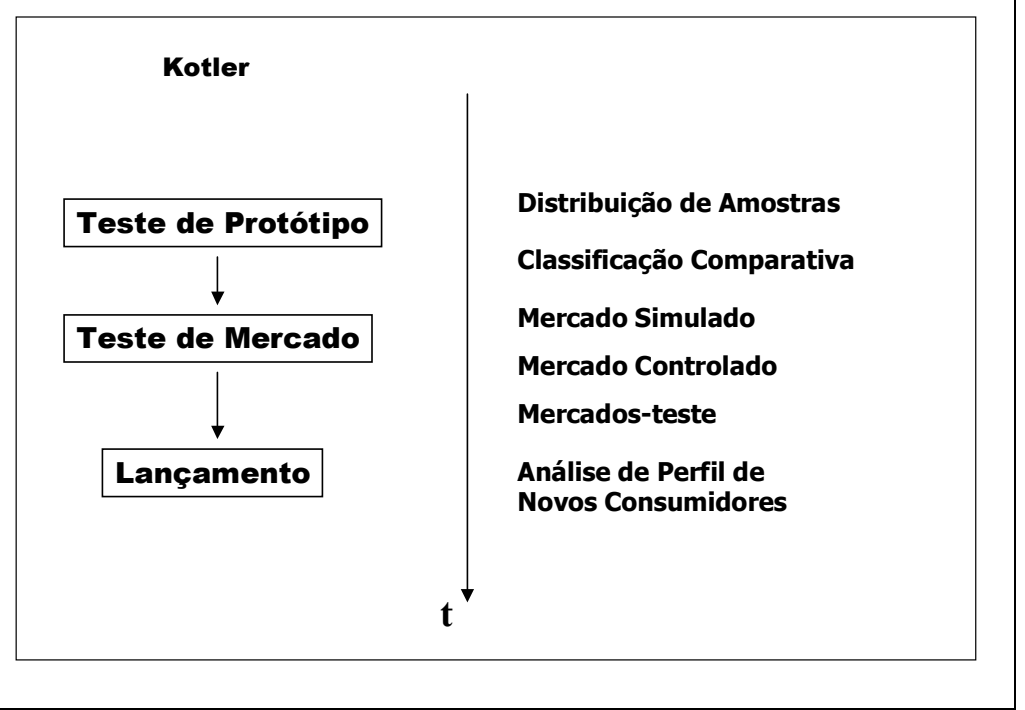

Figura 9 - Técnicas para a preparação da comercialização, estruturadas sobre o modelo de Kotler

\section{A utilização de metodologias organizacionais para o desenvolvimento de produtos}

Com a necessidade de se diminuir o tempo de desenvolvimento de produtos, demandada pela globalização da economia e pelo decorrente surgimento de um novo perfil de consumidor, as empresas tiveram de proceder à utilização de novas formas de condução dos procedimentos relacionados com o ciclo de criação e produção de novos produtos - Hartley (1992). A engenharia concorrente (ou engenharia simultânea) viria a se tornar a metodologia de organização do trabalho dominante na área nos anos 80 , introduzindo o foco na redução do distanciamento entre projeto e fabricação, a par do trabalho interfuncional na área técnica, realizado dentro do conceito de paralelismo temporal na execução das tarefas. Nos anos 90, o desenvolvimento integrado de produto veio a se impor progressivamente, dadas as dificuldades relacionadas com a alta complexidade de criação de novos produtos sob o ponto de vista mercadológico. dadas as dificuldades relacionadas com a alta complexidade de criação de novos produtos e a pressão do mercado por inovação, diminuindo os prazos de desenvolvimento de produtos. 


\subsection{A engenharia concorrente}

A engenharia concorrente consiste, essencialmente, de dois elementos componentes: um de natureza metodológica e outro de natureza tecnológica. Em termos de metodologia, a engenharia concorrente caracterizou-se como um modo de organizar as tarefas do desenvolvimento do produto e da sua produção com base numa redistribuição do faseamento seqüencial de atividades convencionalmente adotado até então, de modo a obter paralelismo (concorrência temporal) na execução das mesmas (ver Figura 10). A par disso, introduziu a noção da execução do desenvolvimento do produto conduzida por uma equipe multidisciplinar de técnicos em Engenharia, baseada numa abordagem que, àquela altura, havia sido introduzida pela, entretanto, mal-sucedida, Reengenharia.

$\mathrm{Na}$ verdade, ao se constituir uma equipe com profissionais atuantes nas áreas técnicas inerentes à execução do ciclo de obtenção do produto, tencionava-se obter a criação de interfaces "naturais" entre as mesmas. Assim, procurava-se suprir a inexistência de mecanismos formais para o estabelecimento de comunicação eficaz entre as diversas funções técnicas.

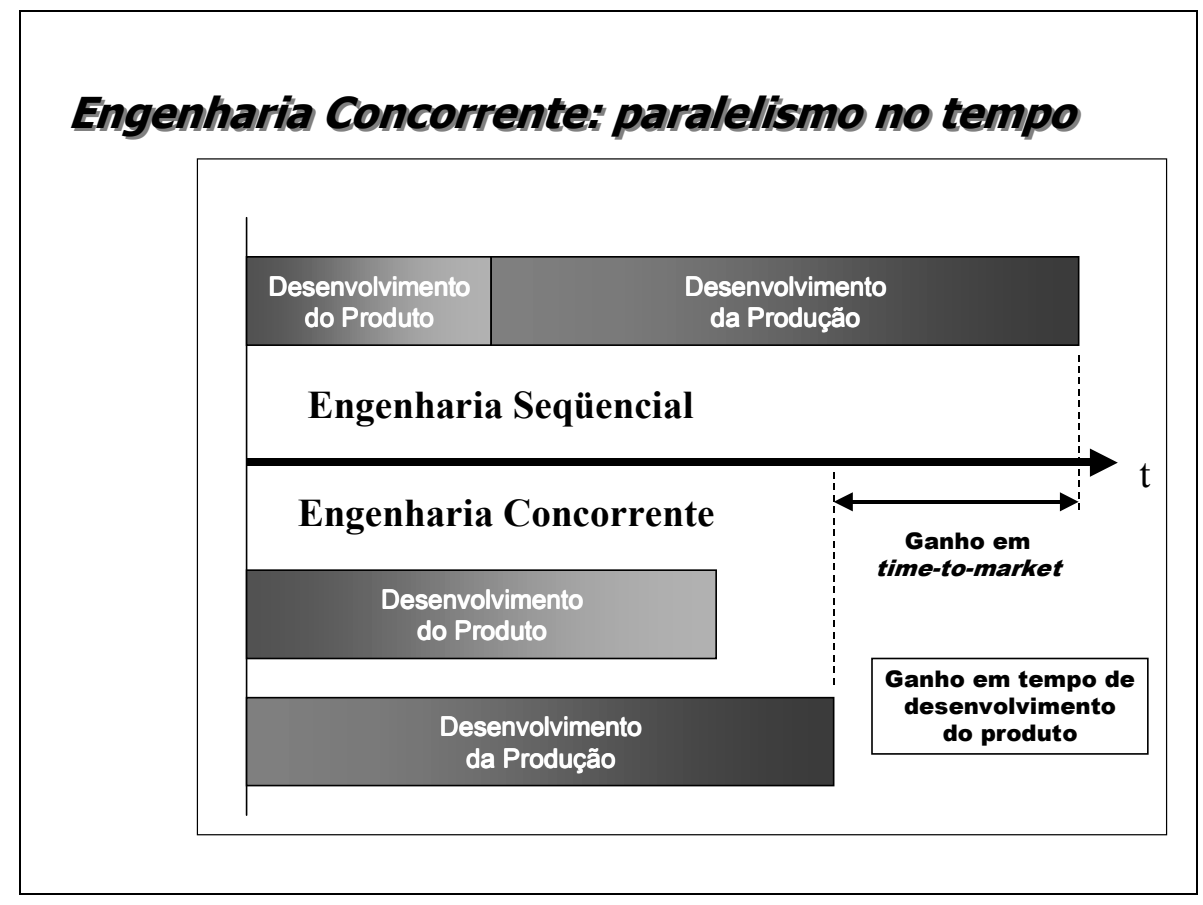

Figura 10 - Engenharia Concorrente: redução em time-to-market

O paralelismo temporal entre as atividades de desenvolvimento do produto e de desenvolvimento da produção (incluindo a fabricação) viabiliza um aumento do tempo disponível para a execução do desenvolvimento do produto, permitindo obter projetos mais bem elaborados. Por hipótese, o desenvolvimento da produção poderá ter seu tempo de execução, até mesmo, reduzido, uma vez que problemas de produção podem ser potencialmente sanados pelo fato do projeto do produto contemplar mais adequadamente as questões de produção desde o início do ciclo de desenvolvimento.

Com a realização de ambas as atividades em paralelo, presumivelmente, pode-se chegar ao término de ambas antes do que ocorreria se viessem a ser efetuadas em seqüência fixa. Esta antecipação da finalização do prazo de transcurso das atividades de desenvolvimento corresponderá a uma possível antecipação da colocação do produto no mercado, a desejada diminuição do valor do parâmetro timeto-market do produto. 
O paralelismo no transcurso entre as atividades de desenvolvimento do produto e de desenvolvimento da produção está associado, também, ao fato de que os profissionais ligados às funções técnicas atuantes numa e noutra atividade deverão trocar informações entre si ao longo da execução das mesmas. Isto determina a diminuição do clássico distanciamento entre o projeto e a fabricação do produto, decorrente da própria especialização das atividades técnicas, cujos efeitos tornaram-se mais acentuados a partir do período pós-Segunda Guerra Mundial (MILLER, 1993).

Contudo, deve-se observar que o projetista não deixa de ser o principal condutor do projeto, apesar de já não ser seu único executor, na prática. Além disso, estará abastecido por um manancial maior de informações referentes à produção do produto, de fato, um potencial facilitador na realização de sua atividade, e contará, ainda, com mais tempo disponível para a execução da sua atividade.

A abordagem proposta pela engenharia concorrente apóia-se numa componente metodológica e noutra tecnológica (PRASAD, 1996). A primeira assenta-se sobre a introdução do paralelismo temporal na execução das atividades de desenvolvimento do produto e da sua produção, e também sobre o emprego do trabalho multidisciplinar e multifuncional (Figura 11).

As dificuldades relativas ao planejamento e controle das diversas tarefas efetuadas em regime de paralelismo temporal suscitaram a introdução, na área do desenvolvimento de produtos, de métodos e técnicas da área de gestão de projetos, anteriormente já dominadas no âmbito da gestão empresarial (MEREDITH \& MANTEL, 2000). Este tema é amplamente discutido, por exemplo, através das obras editadas pelo instituto norte-americano Project Management Institute (PMI).

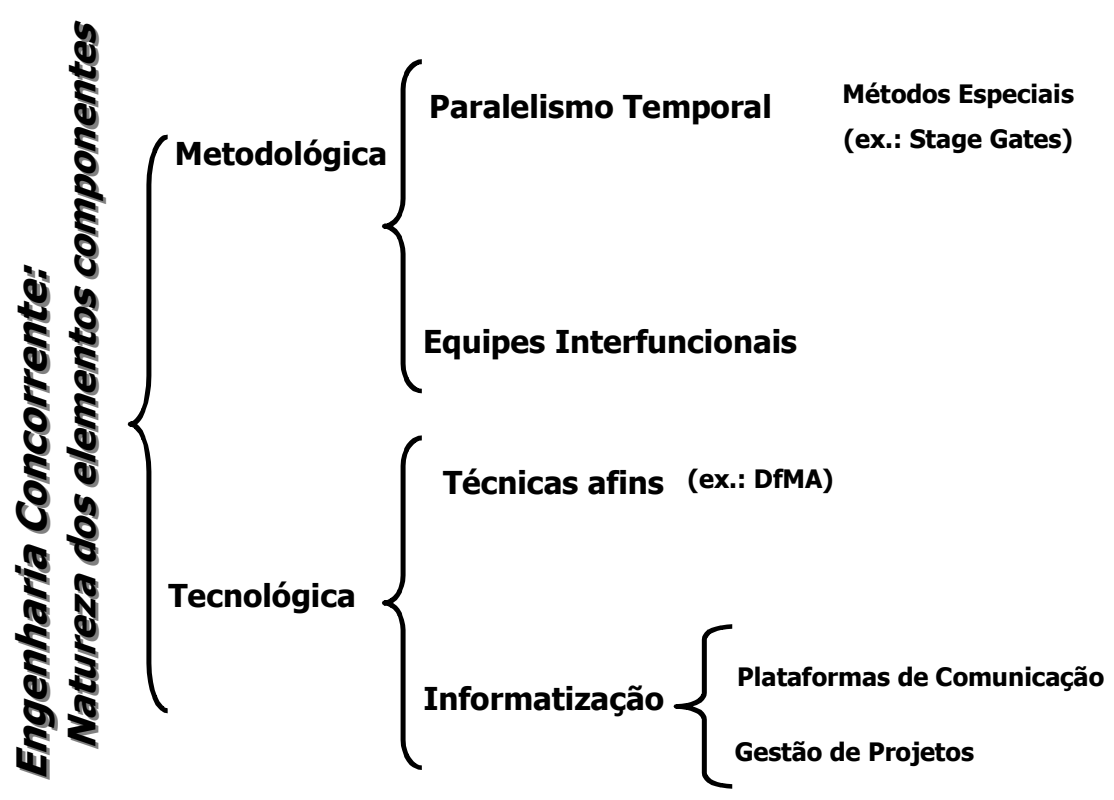

Figura 11 - Engenharia Concorrente: componentes metodológica e tecnológica

Quanto à sua natureza tecnológica, a engenharia concorrente também apresenta-se subdividida em elementos componentes diversos. Em parte, apóia-se no emprego de técnicas de desenvolvimento de produto cujos objetivos tenham afinidade de proposição com a filosofia da engenharia concorrente. É o caso, por exemplo, do projeto orientado à fabricação e montagem (DfMA), que também visa diminuir o distanciamento entre projeto e fabricação. Mas a natureza tecnológica remete, ainda, à utilização de tecnologia de base computacional, mais especificamente, visando dar suporte ao planejamento e controle das tarefas de projeto, com destaque também para a efetivação de uma comunicação mais adequada entre os membros da equipe interfuncional. 


\subsection{O desenvolvimento integrado de produto}

O desenvolvimento integrado de produto, conceito surgido ainda nos anos 80 (ANDREASEN \& HEIN, 1987), tornou-se mais aceito e difundido a partir dos anos 90 (PRASAD, 1997). Partindo da mesma base legada pela engenharia concorrente, especialmente, no que diz respeito ao trabalho em equipe, sua proposta fundamental consistia numa extensão da aplicação desse conceito a todas as áreas envolvidas no desenvolvimento de produtos, sem circunscrição apenas às funções de Engenharia (ver Figura 12). Note-se que alguns atores anteriormente menos correlacionados a essa atividade passaram a ter papel bem mais relevante devido ao contexto geopolítico introduzido pelo fenômeno de globalização da economia. Este foi o caso, por exemplo, dos profissionais ligados à área judicial, dada a importância que a proteção à propriedade intelectual veio a ter contemporaneamente.

Esta proposta de trabalho colaborativo, contudo, passa necessariamente pela gestão das visões díspares, eventualmente conflitantes, entre as diversas funções profissionais em interação. Assim, ao contrário da engenharia concorrente, a gestão da interfuncionalidade, neste contexto, passa a ter de ser gerenciada de modo mais proativo e eficiente.

De fato, desde cedo, ficou claro que o fortalecimento do fluxo de informação entre as diversas funções viria a demandar esforços maiores que a singela constituição de grupos de pessoas oriundas de diferentes áreas de conhecimento. Afora reforçar a predisposição ao relacionamento interpessoal, através de técnicas de gestão de equipes, mostrou-se necessário que os integrantes desses grupos estivessem devidamente instrumentados para a concretização do intercâmbio de informações num nível tecnicamente aceitável. A capacitação para a compreensão recíproca sobre a realidade das várias áreas também passa a ser enfocada. Esta preparação corresponde também a uma definição precisa do conteúdo da informação a ser trocada, bem como à sua devida formatação, o que constitui um dos principais objetos de preocupação do desenvolvimento integrado de produto: a questão do interfaceamento de informações entre as funções, assim construindo as bases do trabalho interfuncional.

\section{Atores no cenário do Desenvolvimento Integrado de Produto}

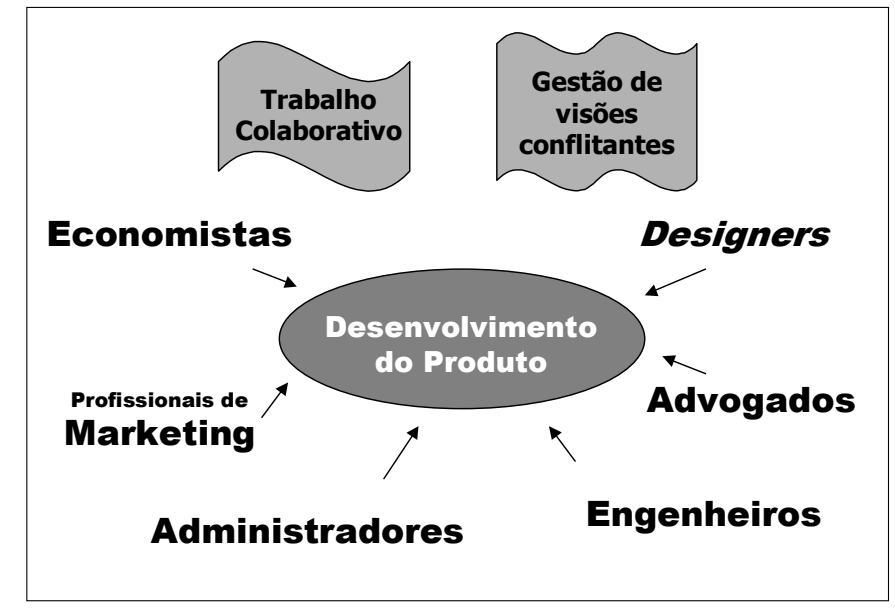

Figura 12 - As diversas funções profissionais em interação no cenário do desenvolvimento integrado de produto

\subsection{A estruturação do negócio com base na gestão de produto}

No final dos anos 90, em tempos de economia globalizada, o oferecimento de produtos com características de diferenciação especificamente orientadas à satisfação do cliente constituiria um dos elementos cruciais capazes de assegurar o sucesso de um empreendimento. Em longo prazo, para que esta orientação possa vir a ser persistente e consistentemente mantida pela empresa, a estratégia de 
negócio da mesma deverá focar a questão da preservação (ou ampliação) da sua posição de mercado através da manutenção da satisfação de seus clientes. Mas como obter este intento se o cliente está a demandar produtos de modo cada vez mais exigente, sob todos os aspectos ?

Este tópico está inerentemente relacionado com a inovação em produto e a inovação de negócio, constituindo objeto central de análise de uma nova abordagem nascida nesse contexto, cujo conceito ainda encontra-se em desenvolvimento: o product-based business (PATTERSON \& FENOGLIO, 1999). É proposta a estruturação do negócio da empresa com base na adequada gestão do portfolio de produtos da mesma, incorporando a inovação de forma permanente ao procedimento de geração planejada de novos produtos como fator diferencial de competitividade. Assim, a geração de produtos passa a constituir um processo de negócio embasado na inovação, a ser permanentemente incorporado ao dia-a-dia da empresa.

Para muitas empresas, a inovação é encarada como uma questão basicamente relacionada com o aporte tecnológico, referente a produto ou a processo produtivo, aparecendo freqüentemente sob a forma de invenção. Contudo, dependendo da situação específica estrutural e conjuntural de cada empresa e dos mercados em que atua, esta visão poderá estar incidentalmente equivocada (PARASURAMAN \& COLBY, 2002). Visto pela perspectiva do cliente, a inovação está objetivamente vinculada a novas (ou melhores) maneiras de atendimento das suas necessidades. Isto poderá, eventualmente, dispensar o investimento em tecnologia, talvez apenas substituído pela viabilização de uma percepção mais precisa dos interesses do cliente (PATTERSON, 1993).

\section{Modelos para o Processo de Desenvolvimento de Produtos e gestão dos ciclos de vida.}

A consideração de que o desenvolvimento de produtos deva ser considerado um processo de negócio (denominado Processo de Desenvolvimento de Produtos - PDP), a ser permanentemente gerido pela empresa, conduziu ao aparecimento de modelos de gestão de características bem diversas dos modelos de estruturação de atividades comentados anteriormente (no tópico 5 deste trabalho), os quais procuravam descrever de forma sistemática a atividade de cada profissional individualmente envolvido com o desenvolvimento de produtos.

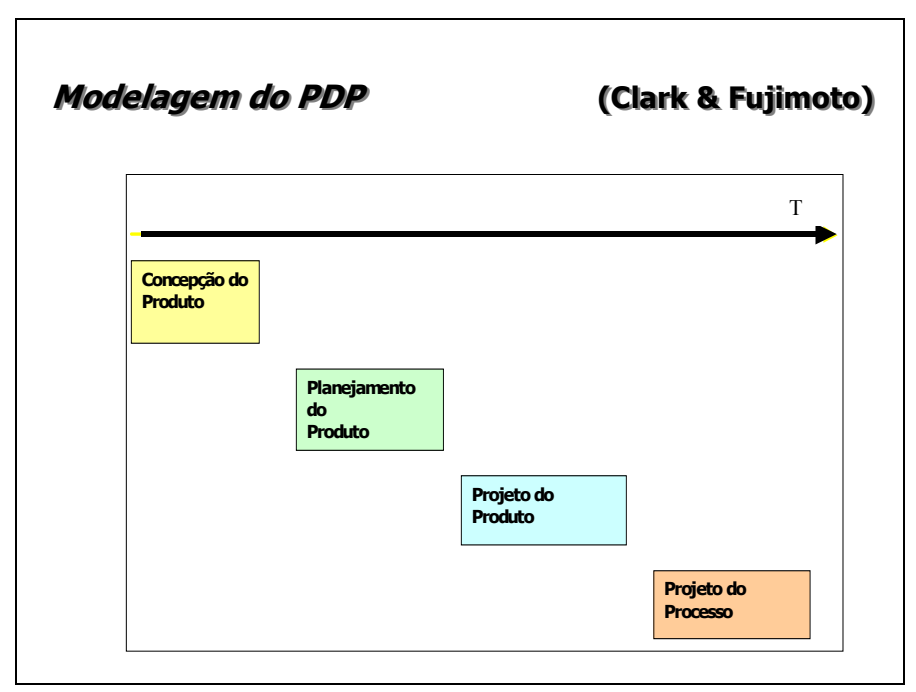

Figura 13 - Modelo de Clark \& Fujimoto (1991) para o processo de desenvolvimento de produto (PDP) 


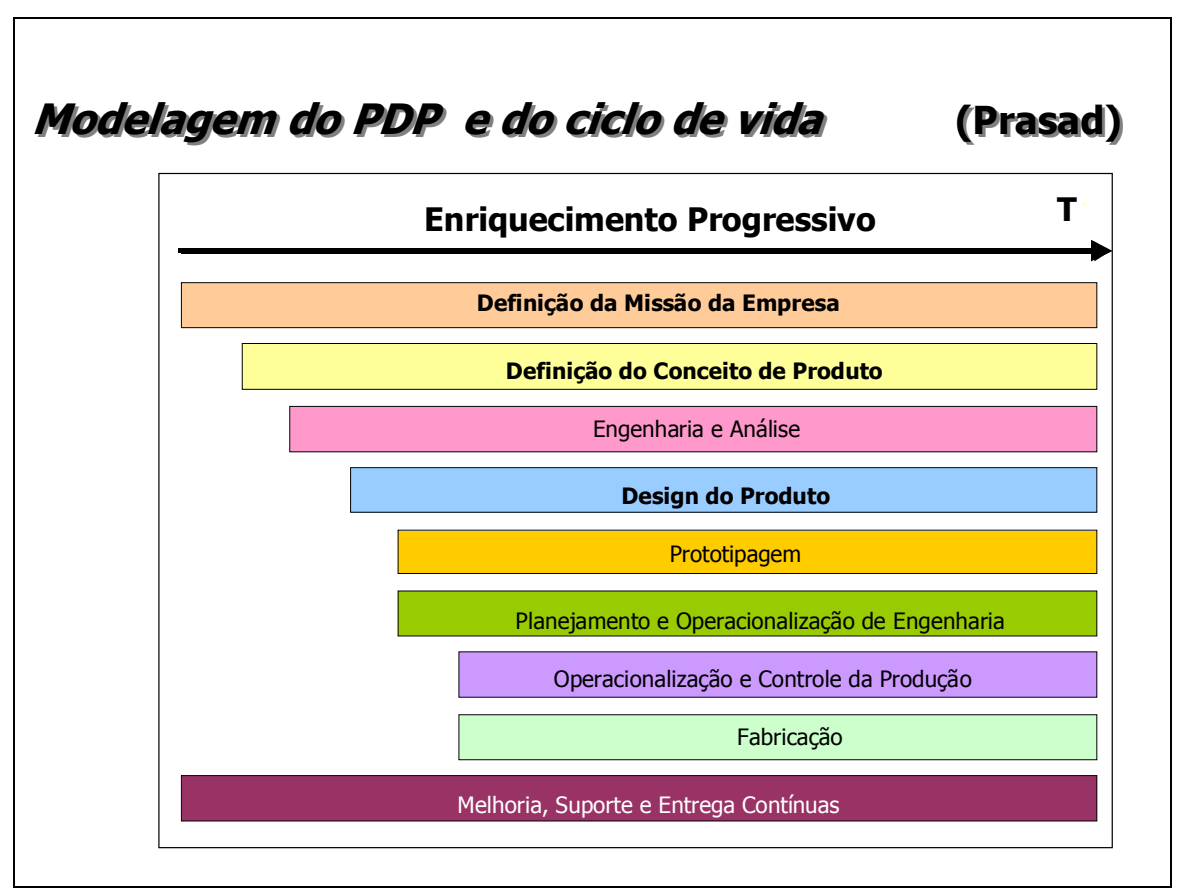

Figura 14 - Modelo de Prasad (1997) para o PDP e o ciclo de vida de produto

Os modelos de descrição do PDP englobam a maioria das atividades de planejamento, execução e controle relacionadas com o desenvolvimento de produto. Na verdade, normalmente, aparecem como a parte principal de modelos de representação do ciclo de vida do produto, freqüentemente embasados no conceito de paralelismo temporal de atividades proposto pela engenharia concorrente. Exemplos de modelos deste gênero são sugeridos ou analisados nos trabalhos de Clark \& Fujimoto (1991), Prasad (1997), Rozenfeld (1997), Ulrich \& Eppinger (2000) e Cunha et al. (2003) - ver Figuras 13, 14, 15 e 16.

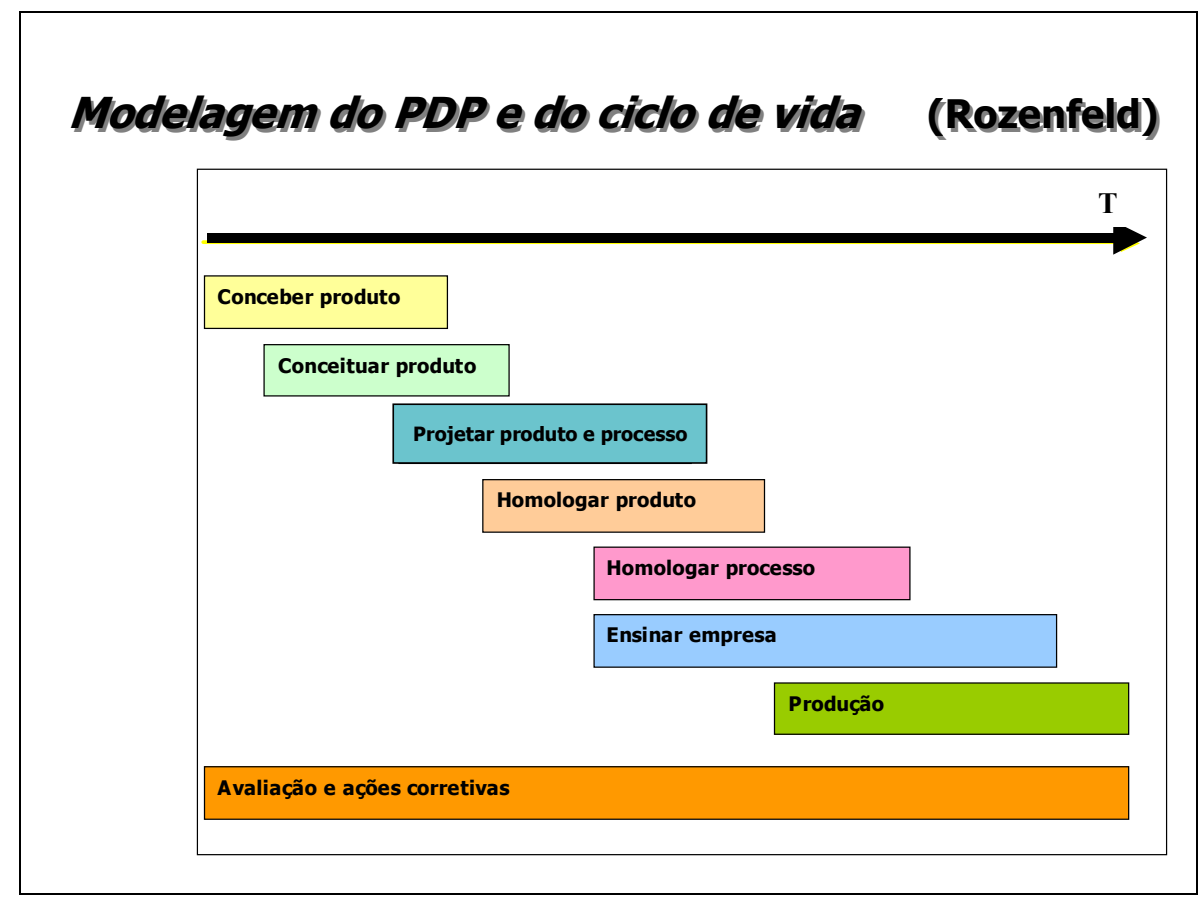

Figura 15 - Modelo proposto por Rozenfeld (1997) para o PDP e o ciclo de vida de produto 


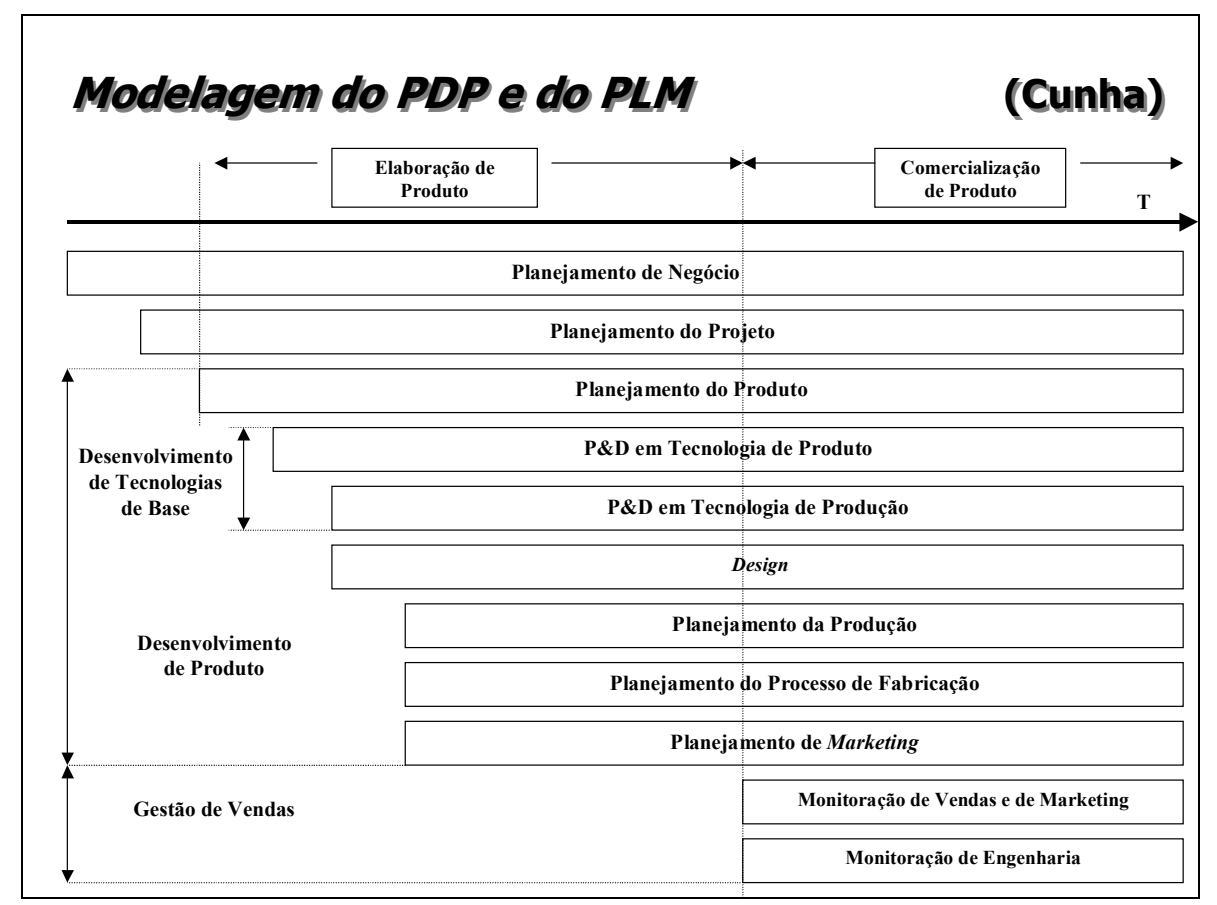

Figura 16 - Modelo proposto por Cunha et al.(2003) para estruturação da gestão do ciclo de vida de produto

Já Cooper (1993) introduziu um conceito oriundo da área de gestão de projetos, denominado Stage Gates, que veio a se tornar bastante conhecido. Pela aplicação do conceito de gate, a execução do desenvolvimento de produtos passa a contar com pontos de controle pré-estabelecidos ao longo do processo. Diversamente dos pontos de controle do tipo milestone (marcos referenciais), os pontos do tipo gate (portões) sujeitam a continuidade do projeto à aprovação de resultados parciais quanto ao produto e ao próprio andamento do projeto com base em critérios previamente definidos.

Do ponto de vista do modo de organização do trabalho, dentro dos modelos para a organização da gestão do ciclo de vida do produto, é esperada a aplicação, de forma mais consolidada possível, dos princípios do trabalho interfuncional, de modo a que os atores participantes do processo tenham fortemente introjetada a compreensão sobre o âmago e os contornos inerentes à atividade de cada agente e de cada função no processo.

\section{Conclusões: A Evolução dos Modos de Gestão de Desenvolvimento de Produtos}

Conforme o contexto analisado neste trabalho, ao longo de um período de escala secular, ocorreu uma considerável mudança nos modos de gestão do desenvolvimento de produtos, devido, basicamente a duas causas. A primeira relaciona-se a uma mudança de ambiente de mercado (a principal); a segunda, à evolução tecnológica, respectivamente caracterizando-se da seguinte maneira:

- Aumento do nível de competitividade de mercado, devido à configuração de um progressivo equilíbrio entre demanda e oferta, ocasionado pelo aumento da produção ao longo do período; isso determinou o surgimento de um cliente mais exigente quanto à qualidade do produto (entendida, principalmente, como o atendimento das suas necessidades pelo mesmo), alicerçado no poder de opção entre as diversas alternativas que lhe são oferecidas; este fato foi, ainda, acentuado pelo surgimento de mercados de dimensões globais, mais recentemente;

- Incremento da complexidade tecnológica, tanto em nível de tecnologia de produto e de processo produtivo, como das técnicas de apoio à execução das tarefas a cargo do desenvolvimentista do produto, que possibilitou a realização dos mais diversos produtos e a concretização de idéias inovadoras. 
Para fazer frente a essas mudanças de cenário, as empresas passaram a organizar-se de modo a oferecerem produtos dentro de um novo paradigma de atuação quanto ao seu desenvolvimento, caracterizado da seguinte forma:

- As visões fracionadas, fortemente disciplinares, específicas de cada área de conhecimento interveniente no desenvolvimento do produto, passaram a ceder lugar a uma visão integradora, que agregasse as diversas funções profissionais envolvidas;A preocupação em definir as características de produto com base, fundamentalmente, em conceitos (e ganhos) de ordem tecnológica cedeu espaço, progressivamente, à preocupação com a compreensão dos interesses de mercado e do cliente e à necessidade de consolidar o foco na agregação de valor ao produto;

- A aplicação de tecnologias de suporte, em especial, a de base computacional (com destaque para o software) passou a ter papel cada vez mais fundamental no desenvolvimento do produto, chegando a condicionar o modo operacional da empresa e do projetista - cujo espaço de ações fica, muitas vezes, restringido pelas limitações que passam a lhe ser impostas pela utilização dos sistemas computacionais;

- Em termos de diferencial competitivo, o foco principal das atenções no mundo empresarial passa a ser a obtenção de produtos que atendam cada vez melhor às necessidades e expectativas dos clientes, o que, além de determinar a preocupação em prospectar os interesses dos consumidores, conduz, também, à incorporação da inovação ao processo de geração de novos produtos;

- Ocorrência, também, de uma maior necessidade em empregar métodos e técnicas de gestão de projetos (controladoria) para fazer frente ao crescimento da complexidade da atividade de gestão do desenvolvimento de produtos, suscitado pelo advento das modernas metodologias de organização na área, como a engenharia concorrente;

- Revisão da definição de produto, que passou a ser mais abrangente, contemplando não apenas o bem-núcleo (dimensão genérica), mas também os serviços que lhe são associados; isso viria a determinar mudanças da própria percepção sobre a forma de organização da empresa e de seus sistemas de produção.

A evolução dos modos de gestão do desenvolvimento de produtos propiciou, portanto, mudanças significativas no modo de atuação dos profissionais envolvidos na atividade, e, até mesmo, na forma como a própria área hoje se visualiza.

Em termos do conhecimento intrínseco à área, há vários tópicos a serem ainda melhor estudados, entre os quais, podem-se apontar os seguintes:

- Estabelecimento de modos eficientes de gestão dos grupos interfuncionais;

- Estabelecimento do papel de cada função profissional no cenário de realização do desenvolvimento integrado de produto;

- Estabelecimento de interfaces técnicas capazes de viabilizar a comunicação eficaz entre as funções (não apenas em termos de informatização, mas também das definições formais inerentes ao processo de transmissão da informação);

- Estabelecimento, em nível formal, do fluxo completo de informações:

- Entre as diversas funções;

- Entre as diversas etapas do processo de desenvolvimento do produto;

- Entre as diversas técnicas aplicadas ao longo da execução dessas etapas;

- Desenvolvimento de ferramentas computacionais que permitam o mapeamento preciso do conjunto completo de informações apropriáveis e utilizáveis ao longo do ciclo de vida do produto (o que se poderia, talvez, denominar de tecnologia e-PLM); esta ação supõe o seguinte:

- Efetiva compreensão do ciclo completo do desenvolvimento de produto e, possivelmente, também do desenvolvimento de sua produção, em termos de etapas incorrentes, da utilização de métodos e técnicas de suporte, e da informação produzida e requerida por estas; A criação de modelos de referência para suporte à implementação do e-PLM, conforme analisado por McGrath (1996), evitando a 
imposição de soluções informatizadas que engessem de modo distorcido e incompleto o fluxo de informações subjacentes ao PLM (um pouco à moda do que ocorre, com freqüência, na implementação de sistemas de informação, de que é exemplo a tecnologia ERP).

Com referência à aplicação do conhecimento inerente à gestão do desenvolvimento de produtos ao meio empresarial, há várias questões a merecerem atenção, desafiando a capacidade e a argúcia de gestores. Entre esses, citam-se os seguintes, sempre consoante a sua efetiva adequação às especificidades de cada empresa:

- Disseminação da cultura da estruturação formal do procedimento de desenvolvimento de produtos;

- Desenvolvimento de modelos estruturais de representação do ciclo de vida de produto, novamente;

- Estabelecimento, mesmo em nível informal, de política de incremento à viabilização e otimização do fluxo de informações relacionadas com o ciclo de obtenção do produto;

- Investimento em formação e capacitação de analistas e gestores do desenvolvimento de produtos, o que supõe a necessidade de ações concretas relacionadas com a área do ensino superior;

- Transformar o desenvolvimento de produtos, efetivamente, em processo de negócio permanente no ambiente industrial, o que requer o seguinte:Incorporação da inovação como elemento estrutural deste processoImplantação de políticas de gestão do conhecimento empresarial e de gestão da tecnologia como suporte à inovação.

Sendo a gestão do desenvolvimento de produtos um tema assentado, cada vez mais, sobre uma base de conhecimento caracterizada pela diversidade disciplinar, é natural que a evolução do estudo relativo ao mesmo tenha um elevado grau de complexidade, o que, no mais das vezes, dificulta sua compreensão em nível mais detalhado. Trata-se, na verdade, de um tema cuja natureza tem vindo a caracterizar-se, em última instância, pelo caráter transdisciplinar, cuja linha de evolução parece apontar inequivocamente no sentido do aprofundamento das relações entre as diversas áreas de conhecimento em interação (conforme quadro comparativo proposto a seguir).

\begin{tabular}{|c|c|c|c|c|}
\hline $\begin{array}{c}\text { Modelo de } \\
\text { organização do DP }\end{array}$ & $\begin{array}{c}\text { Agente(s) da execução } \\
\text { de atividades }\end{array}$ & Temporalidade & $\begin{array}{c}\text { Participação da } \\
\text { Administração no } \\
\text { processo decisório }\end{array}$ & $\begin{array}{l}\text { Natureza do } \\
\text { conhecimento }\end{array}$ \\
\hline $\begin{array}{l}\text { Projetual (ex.: } \\
\text { Kotler, Pahl \& } \\
\text { Beitz) }\end{array}$ & $\begin{array}{l}\text { Projetistas, profissionais } \\
\text { de marketing }\end{array}$ & Caráter eventual & Nenhuma ou mínima & Disciplinar \\
\hline $\begin{array}{l}\text { Engenharia } \\
\text { Concorrente }\end{array}$ & $\begin{array}{l}\text { Pessoal envolvido com } \\
\text { "áreas técnicas" } \\
\text { (Engenharia) }\end{array}$ & $\begin{array}{l}\text { Caráter permanente; } \\
\text { ausência da noção de } \\
\text { processo }\end{array}$ & Em nível de gerência & $\begin{array}{l}\text { Multidisciplinar, } \\
\text { tendente ao } \\
\text { interdisciplinar (ex.: } \\
\text { treinamento em } \\
\text { DfMA) }\end{array}$ \\
\hline $\begin{array}{l}\text { Desenvolvimento } \\
\text { Integrado de } \\
\text { Produto }\end{array}$ & $\begin{array}{l}\text { Pessoal com formação } \\
\text { diversificada, exercendo } \\
\text { diferentes funções }\end{array}$ & $\begin{array}{l}\text { Caráter permanente; } \\
\text { tendente à percepção } \\
\text { da noção de processo }\end{array}$ & $\begin{array}{l}\text { Em nível de alta } \\
\text { gerência }\end{array}$ & Interdisciplinar \\
\hline $\begin{array}{l}\text { Gestão do Ciclo de } \\
\text { Vida do Produto }\end{array}$ & $\begin{array}{c}\text { Pessoal de todas as } \\
\text { áreas e de todas as } \\
\text { funções intervenientes } \\
\text { no DP }\end{array}$ & $\begin{array}{l}\text { Caráter permanente } \\
\text { processual }\end{array}$ & $\begin{array}{c}\text { Em nível de alta } \\
\text { administração e de } \\
\text { gerência }\end{array}$ & Transdisciplinar \\
\hline
\end{tabular}

Figura 17 - As diversas formas de organização do desenvolvimento de produto (DP) e suas tendências

Não parece haver, por outro lado, caminho diverso a trilhar a não ser o do aprofundamento do conhecimento balizado por esta transdisciplinaridade enquanto o acirramento da disputa pelos clientes configurar a tônica da situação de mercado, considerando-se, ainda, que o avanço tecnológico continuará a determinar um incremento em complexidade referente a esta atividade do desenvolvimento de produtos. 


\section{Referências}

ANDREASEN, M. M.; HEIN, L. Integrated Product Development. Bedford: Springer-Verlag. 1987.

BAXTER, M.R. Product Design. Londres: Chapman \& Hall. 1995.

BLESSING, L.T.M. A Process-based Approach to Computer-suported Engineering Design. Cambridge. 1994.

CLARK, K.B.; FUJIMOTO, T. Product Development Performance - Strategy, Organization, and Management in the World Auto Industry. Boston: Harvard Business School Press. 1991.

CLAUSING, D. Total Quality Development: a Step-by-step Guide to Concurrent Engineering. Nova Iorque: ASME Press. 1994.

COOPER, R.G. Winning at New Products: Accelerating the Process from Idea to Launching. Addison-Wesley. 1993.

CRAWFORD, C. M.; DiBENEDETTO, C.A. New Products Management. Boston: McGraw-Hill. 2000.

CUNHA, G.D.; BUSS, C.O.; DANILEVICZ, A.M.F.; ECHEVESTE, M.E.S.; KUYVEN, P.S. A Reference Model to Support Introducing Product Lifecycle Management. In: GONÇALVES, R.J.; JIANZHONG, C.; STEIGER-GARÇÃO, A. Concurrent Engineering: The Vision for the Future Generation - Enhanced Interoperable Systems. Amsterdam: Balkema Publishers.

FRENCH, M.J. Conceptual Design for Engineers. Londres: Springer-Verlag. 1985.

HARTLEY, J.R. Concurrent Engineering: Shortening Lead Times, Raising Quality, and Lowering Costs. Productivity Press. 1992.

HUBKA, V.; EDER, W.E. Theory of Technical Systems - a Total Concept Theory for Engineering Design. Berlin: Springer. 1988.

KOTLER, P. Marketing Management - Analysis, Planning, Implementation, and Control. Londres: Prentice-Hall. 1997.

LEVITT, T. The Marketing Imagination. Nova Iorque: Free Press. 1983.

McGRATH, M.E. Setting the PACE in Product Development: a Guide to Product and Cycle-time Excellence. Washington: Butterworth-Heinnemann. 1996.

MEREDITH, J.R. \& MANTEL JR., S.J. Project Management - A Managerial Approach. John Wiley \& Sons. 2000.

MILLER, L.C.G. Concurrent Engineering Design - Integrating the Best Practices for Process Improvement. Dearborn: Society of Manufacturing Engineers Publications. 1993.

PAHL, G.; BEITZ, W. Engineering Design - A Systematic Approach. Londres: Springer-Verlag. 1996.

PARASURAMAN, A.; COLBY, C.L. Marketing para produtos inovadores: como e por que seus clientes adotam tecnologia. Porto Alegre: Bookman. 2002. 
PATTERSON, M.L. Accelerating Innovation - Improving the Process of Product Development. Nova Iorque: Van Nostrand Reinhold. 1993.

PATTERSON, M.L.; FENOGLIO, J.A. Leading Product Innovation - Accelerating Growth in a Product-Based Business. Nova Iorque: John Wiley \& Sons. 1999.

PROJECT MANAGEMENT INSTITUTE. A Guide to the Project Management Body of Knowledge: PMBOK EE. UU. CD-ROM. 2000.

PRASAD, B. Concurrent Engineering Fundamentals: Integrated Product and Process Organization. Londres: Prentice-Hall. 1996.

PRASAD, B. Concurrent Engineering Fundamentals: Integrated Product Development. Londres: Prentice-Hall. 1997.

PUGH, S. Total Design: Integrated Methods for Successful Product Engineering. Wokingham: Addison-Wesley. 1991.

ROOZENBURG, N.F.M.; EEKELS, J. Product Design: Fundamentals and Methods. Nova Iorque: John Wiley \& Sons. 1995.

ROZENFELD, Henrique. Modelo de Referência para o Desenvolvimento Integrado de Produtos. In: ENCONTRO NACIONAL DE ENGENHARIA DE PRODUÇÃO, 17. Gramado, 1997. Anais. Porto Alegre: Associação Brasileira de Engenharia de Produção, 1997.

SHIGLEY, J.G. Mechanical Engineering Design. Oakland: Mc-Graw-Hill. 1981.

SUH, N. P. The Principles of Design. Nova Iorque: Oxford University Press. 1990.

ULMANN, D.G. The Mechanical Design Process. Nova Iorque: McGraw-Hill. 1997.

ULRICH, K.T.; EPPINGER, S.D. Product Design and Development. Nova Iorque: McGraw-Hill. 2000. 